\title{
PERGESERAN PENGGUNAAN BAHASA JAWA KE BAHASA INDONESIA DALAM KOMUNIKASI KELUARGA DI SLEMAN
}

\author{
Wirayudha Pramana Bhakti \\ IAIN Pekalongan \\ wirayudhapramanab@gmail.com
}

\begin{abstract}
ABSTRAK
Pergeseran bahasa terjadi karena adanya kontak antar bahasa, suatu bahasa dapat menggeser bahasa lain. Kabupaten Sleman merupakan salah satu daerah pusat ekonomi dan pendidikan yang memiliki tingkat keragaman serta pertumbuhan yang tinggi sehingga sangat rentan terjadi pergeseran bahasa. Sebagai masayarakat Jawa yang menjunjung tinggi unggah-ungguh, masyarakat Sleman seharusnya semakin terbiasa dan mahir berbahasa Jawa, mulai dari ngoko sampai krama. Akan tatapi, bahasa Indonesia justru sering digunakan sebagai bahasa ibu dalam berkomunikasi di lingkungan keluarga. Melalui kajian sosiolingustik dengan pendekatan fenomenologi, tulisan ini akan menguraikan faktor-faktor penyebab pergeseran penggunaan bahasa Jawa ke bahasa Indonesia dalam komunikasi keluarga di Kabupaten Sleman. Populasi penelitian ini adalah seluruh keluarga yang tinggal di Kabupaten Sleman, sampel penelitian diambil secara acak. Data dikumpulkan melalui metode observasi atau simak serta wawancara. Berdasarkan hasil penelitian yang dilaksanakan pada tahun 2019, ditemukan beberapa faktor penyebab pergeseran bahasa tersebut, antara lain: tingkat pendidikan keluarga, pemilihan bahasa yang lugas dan sopan dalam keluarga, usia keluarga, stratifikasi sosial keluarga, kurangnya pembelajaran bahasa Jawa untuk keluarga, wilayah pemukiman keluarga, serta sikap keluarga terhadap bahasa. Bahasa Indonesia yang digunakan dalam komunikasi keluarga di Kabupaten Sleman didominasi oleh bahasa Indonesia nonformal yang disertai dengan gejala alih kode dan campur kode.
\end{abstract}

Kata Kunci: pergeseran bahasa, bahasa Jawa, bahasa Indonesia, komunikasi keluarga

\begin{abstract}
Language shifts occur due to inter-lingual contact, a language can shift another language. Sleman Regency is one of the areas of economic and educational centers that have a high level of diversity so that it is vulnerable to language shifts. As Javanese society that uphold the value of politeness, the people of Sleman should be able to speak Javanese well. In fact, Indonesian language is often used in communication in the family environment. Through sociolingustic study with phenomenological approach, this article will describe the factors causing the shifting use of Javanese language to Indonesian language in the family communication in Sleman. The population of this study was the entire family living in Sleman, samples of research taken randomly. Data is collected through observation methods and interviews. Based on the results of the research conducted in 2019, there were found factors for language shift, among others: the level of family education, the choice of straightforward and polite language in the family, the age of the family, family social stratification, lack of Javanese language learning for families, family residential areas, and family attitudes to the language. The Indonesian language used in family communications in Sleman is dominated by informal Indonesian language accompanied by a code switching and code mixing.
\end{abstract}

Keywords: language shift, Javanese language, Indonesian language, family communication 


\section{A. PENDAHULUAN}

Bahasa merupakan salah satu wujud budaya yang digunakan sebagai alat komunikasi yang selalu hidup dan berkembang. Perkembangan sebuah bahasa dapat berwujud perubahan atau pergeseran. Adanya pergeseran bahasa yang disebabkan oleh adanya faktor kemultibahasaan atau kedwibahasaan yang berkembang di masyarakat. Pada umumnya masyarakat di Indonesia berkomunikasi dalam kehidupan sehari-hari dapat menggunakan lebih dari satu bahasa. Istilah kedwibahasaan (bilingualism) tersebut pada umumnya digunakan berkaitan dengan kemampuan serta kebiasaan menggunakan dua bahasa. Kedwibahasaan juga dapat disebut dengan kegandabahasaan atau multilingualism. Istilah kedwibahasaan dapat dipakai untuk dua pemaknaan yang saling berkaitan tetapi berbeda, yaitu kemampuan penutur untuk menggunakan dua bahasa maupun kebiasaan memakai dua bahasa dalam interkasi dan komunikasi sehari-hari. Istilah yang pertama dapat diartikan sebagai bilingualitas, sedangkan yang kedua berarti bilingualisme (Nababan, 1991: 4).

Daerah Istimewa Yogyakarta memiliki 4 kabupaten dan 1 kota madya, yaitu Kabupaten Sleman, Kabupaten Bantul, Kabupaten Kulon Progo, Kabupaten Gunung Kidul, serta Kota Madya Yogyakarta sebagai pusat DIY. Wilayah tersebut dikenal sebagai daerah yang sangat memegang teguh budaya dan bahasa, terutama bahasa Jawa. Daerah tersebut sangat kental dengan nuansa budaya yang adiluhung. Salah satunya yaitu berkembangnya bahasa Jawa di Yogyakarta, mulai dari ngoko sampai krama inggil. Daerah Istimewa Yogyakarta, termasuk dalam hal ini daerah Surakarta, memiliki bahasa Jawa yang khas dan sedikit berbeda dengan di daerah Jawa. Kekhasan bahasa kedua wilayah tersebut dipengaruhi oleh adanya dua pusat kerajaan yang masing-masing bahasa yang dimiliki dijadikan norma bahasa Jawa yang baku (Pujiyati Suyata dan Suharti, 2007: 3).

Bahasa Jawa tidak hanya digunakan dalam interaksi sehari-hari, tetapi juga masuk dalam kurikulum pembelajaran di sekolah dasar dan menengah atas. Oleh sebab itu, mata pelajaran bahasa Jawa memperhatikan kedudukan maupun fungsi bahasa Jawa. Sebagai bahasa daerah, bahasa Jawa berkedudukan sebagai; (1) lambang identitas suatu daerah, (2) lambang kebanggaan suatu daerah, dan (3) alat interaksi keluarga dan masyarakat suatu daerah. Sedangkan sebagai mata pelajaran Bahasa, Sastra, dan Budaya Jawa fungsi bahasa Jawa, yaitu; (1) sarana untuk meningkatkan pengetahuan dan keterampilan dalam rangka pengembangan serta pelestarian budaya Jawa, (2) sarana untuk pembina rasa bangga terhadap bahasa Jawa, (3) sarana untuk menyebarkan penggunaan bahasa Jawa yang baik dan benar untuk berbagai keperluan, (4) sarana peningkatan pengetahuan dan keterampilan yang bertujuan untuk mengembangkan ilmu pengetahuan, teknologi, dan seni, serta (5) sarana pemahaman budaya Jawa melalui kesusasteraan Jawa. (Muh. Arafik \& Rumijan, 2016: 59)

Dengan demikian, masyarakat Yogyakarta mampu mempertahankan dan melestarikan bahasa daerah yang dimilikinya. Bahasa Jawa sebagai bahasa daerah memiliki nilai budaya dan etika yang sangat luhur. Dalam pembelajaran bahasa Jawa terdapat materi unggah-ungguh basa Jawa yang salah satunya mengajarkan etika berbicara dengan orang tua atau dengan orang yang memiliki starta sosial yang 
lebih tinggi. Oleh sebab itu, wajar jika bahasa Jawa sangat sesuai digunakan untuk berkomunikasi dan berinteraksi baik di tingkat keluarga maupun masyarakat, di samping juga menggunakan bahasa Indonesia. Fenomena penggunaan dua bahasa tersebut sering disebut dengan istilah dwibahasa.

Fenomena bahasa tersebut antar lain dipengaruhi oleh adanya tingkat keragaman baik ekonomi, pendidikan, sosial, dan budaya yang dimiliki oleh di suatu daerah. Akhmad Muawal Hasan \& Amika Wardhana (2016: 4), menyatakan bahwa Daerah Istimewa Yogyakarta merupakan salah satu daerah yang memiliki tingkat variasi dan keragaman yang tinggi di Indonesia sehingga membuat komposisi penduduknya sangat beragam. Keragaman akan semakin terlihat di wilayah Kabupaten Sleman yang secara geografis berdekatan langsung dengan pusat Kota Yogyakarta. Selain itu, Kabupaten Sleman merupakan pusat perkembangan ekonomi serta pendidikan di Daerah Istimewa Yogyakarta.

Dwibahasa atau bilingulism yang terjadi di Yogyakarta bukan hanya ada di lingkungan formal dan perkantoran. Masyarakat Yogyakarta terbiasa berkomunikasi dengan menggunakan dua bahasa sekaligus, yaitu bahasa Jawa dan bahasa Indonesia. Fenomena umum tersebut juga terjadi di kehidupan masyarakat seharihari yang dimulai dari komunikasi tingkat keluarga sampai lingkungan sosial yang lebih tinggi. Fenomena dwibahasa akan lebih terlihat di daerah perkotaan atau lingkungan yang mempunyai tingkat multikutural yang tinggi. Maka tidak heran jika bahasa Indonesia, terutama bahasa Indonesia ragam nonformal, justru terkadang menjadi bahasa pengantar dan bahasa ibu di lingkungan tersebut. Bahasa tersebut telah berkembang menjadi bahasa zaman sekarang di beberapa wilayah yang memiliki tingkat pertumbuhan ekonomi maupun pendidikan yang relatif tinggi, salah satunya di wilayah Kabupaten Sleman, Daerah Istimewa Yogyakarta.

Pada saat ini, bahasa Indonesia mendapatkan status sebagai bahasa yang bergengsi atau prestisius, yang artinya bahasa tersebut digunakan oleh golongan strata sosial menengah dan berpendidikan, sehingga dianggap sebagai bahasa kaum elit di Indonesia. Pada tahun 2005 Emmerson menyampaikan bahwa jumlah pengguna atau penutur bahasa Indonesia terus mengalami peningkatan yang signifikan, mulai dari 40,5\% pada tahun 1971 naik menjadi $60,8 \%$ pada tahun 1980 , serta mencapai 82,8\% pada tahun 1990 (Sneddon, 2003: 140-142). Dapat dipastikan penutur bahasa Indonesia bertambah pesat pada setiap dasawarsa. Akibatnya, bahasa Indonesia dianggap menggeser peranan bahasa daerah sebagai bahasa ibu maupun bahasa dalam komunikasi maupun interaksi sosial baik di lingkungan keluarga maupun masyarakat. Fenomena tersebut menunjukkan mulai melemahnya pemertahanan bahasa daerah di Indonesia. Sebaliknya, terjadi peningkatan pergeseran bahasa daerah ke bahasa yang lebih bergengsi. Mengamati kondisi zaman yang semakin maju seperti saat ini, bahasa daerah mulai luntur secara perlahan dan mengalami pergeseran. (Tamrin, 2018: 68)

Fenomena pergeseran bahasa juga terjadi di Kabupaten Sleman, Daerah Istimewa Yogyakarta, yaitu kecenderungan penggunaan bahasa Indonesia dari oleh penutur asli bahasa Jawa pada komunikasi dan interaksi tingkat keluarga. Di lihat dari sudut pandang sosiolinguistik, sebagai masayarakat Jawa yang menjunjung tinggi unggah-ungguh, seharusnya masyarakat Sleman semakin terbiasa dan 
semakin mahir berbahasa Jawa, mulai dari ngoko sampai krama. Pada ranah komunikasi keluarga, idealnya anggota keluarga menggunakan bahasa Jawa sebagai bahasa ibu. Bahasa Indonesia sebagai bahasa ibu justru sering digunakan dalam berkomunikasi di lingkungan keluarga, terutama bahasa Indonesia nonformal.

Beberapa hasil penelitian tentang pergeseran bahasa di Indonesia menunjukkan hasil bahwa pergeseran bahasa daerah disebabkan oleh beberapa faktor. Akan tetapi, faktor-faktor tersebut tidak pernah sama dengan faktor-faktor penyebab pergeseran bahasa lainnya (Ibrahim dkk, 2019: 2). Sebagai wilayah yang memiliki tingkat keragaman dan pertumbuhan yang tinggi, Sleman sangat rentan terjadi pergeseran bahasa, khususnya dalam interaksi dan komunikasi di ranah keluarga. Melalui kajian sosiolingustik dengan pendekatan fenomenologi, tulisan ini akan menguraikan faktor-faktor penyebab pergeseran penggunaan bahasa Jawa ke bahasa Indonesia komunikasi keluarga di Kabupaten Sleman.

\section{B. METODE PENELITIAN}

Jenis penelitian ini adalah deskriptif analisis. Populasi penelitian ini yaitu seluruh keluarga yang tinggal di Kabupaten Sleman. Adapun sampel atau responden penelitian diambil secara acak atau random sampling, yaitu keluarga Jawa asli dan menetap di daerah pedesaan, pinggiran kota, maupun daerah perkotaan di Kabupaten Sleman. Data primer dalam penelitian ini adalah data kualitatif yang dikumpulkan melalui metode observasi atau simak serta wawancara. Data sekunder berupa buku, jurnal, arsip, maupun sumber lain yang relevan dengan penelitian. Penelitian dilaksanakan selama kurang lebih satu tahun, yaitu pada tahun 2019.

\section{PERGESERAN BAHASA DAN PEMERTAHANAN BAHASA}

Fenomena pergeseran dan pemertahanan bahasa ibarat dua buah sisi mata uang yang masuk ke kajian sosiolinguistik. Disiplin ilmu tersebut merupakan gabungan dari dua disiplin kelimuan, yaitu sosiologi dan linguistik. Menurut Chaer dan Agustina (2010: 2), sosiolinguistik adalah salah satu bidang antar disiplin ilmu yang mempelajari bahasa berkaitan dengan penggunaan bahasa tersebut di dalam masyarakat. Senada dengan pernyataan tersebut. Soemarsono (2012: 8) menyatakan bahwa sosiolingustik melihat bahasa sebagai salah satu sistem yang berkaitan dengan kehidupan masyarakat. Bahasa dipandang sebagai sebuah sistem yang tidak dapat lepas dari berbagai ciri khas penutur dan dari nilai-nilai sosial budaya yang dipatuhi oleh penutur. Dengan demikian, dapat disimpulkan bahwa sosiolinguistik merupakan ilmu yang mengkaji penggunaan bahasa dan perilaku sosial.

Dari uraian tersebut dapat dimaknai bahwa kajian sosiolinguistik sebenarnya memiliki cakupan kajian yang luas. Bukan hanya mencakup pemilihan dan pemakaian bahasa yang berkaitan dengan fenomena sosial, tetapi juga berkaitan dengan ekonomi, agama, budaya, pendidikan, maupun geografis suatu masyarakat. Oleh karena itu, pergeseran bahasa merupakan salah satu objek kajian yang ada di sosiolinguistik. Dengan sosiolinguistik, adanya fenomena pergeseran bahasa yang terjadi di suatu masyarakat dapat diketahui faktor penyebab, proses pergeseran, serta variasi bahasa yang digunakan. 
Fenomena pergeseran maupun pemertahanan bahasa terjadi karena adanya kontak antar bahasa yang ada di masyarakat. Fakta bahasa yang terjadi di masyarakat bahwa suatu bahasa dapat menggeser bahasa lain atau suatu bahasa tidak dapat tergeser oleh bahasa lain. Bahasa yang tergeser oleh bahasa lain yaitu bahasa yang tidak mampu bertahan karena ada bahasa baru yang digunakan (Sumarsono dan Partana, 2002: 231). Dapat dikatakan bahwa fenomena pergeseran bahasa terjadi jika masyarakat pemakai salah satu bahasa memilih suatu bahasa yang lain untuk menggantikan bahasa yang sebelumnya. Biasanya bahasa lain yang menggeser bahasa awal adalah bahasa yang dominan, lugas, serta bahasa yang memiliki kesan prestise jika digunakan. Hal tersebut merupakan faktor penyebab pergeseran bahasa dari aspek kebahasaan. Sedangkan dalam pemertahanan suatu bahasa dalam sebuah komunitas secara kolektif dapat menentukan untuk melanjutkan penggunaan bahasa yang digunakan sebelumnya, salah satunya karena alasan menjaga tradisi, budaya, maupun kearifan lokal.

Pendapat tersebut senada dengan pernyatan Coulmas (2005: 158-159), bahwa pilihan bahasa baik individu, keluarga, maupun masyarakat merupakan salah satu penyebab terjadinya pergeseran atau pemertahanan suatu bahasa. Bahasa dapat mengalami perubahan dan perkembangan seperti halnya manusia. Oleh sebab itu, bahasa yang diwariskan oleh masyarakat penutur generasi sebelumnya biasanya akan diinovasi dan dikreasikan oleh generasi selanjutnya. Inovasi bahasa tersebut berpotensi membentuk variasi bahasa tertentu sesuai dengan konteks sosial dan budaya yang berkembang. Strata sosial, usia, jenis kelamin merupakan faktor penyebab terjadinya pergeseran bahasa di luar aspek kebahasaan.

Pembagian fungsi dalam masyarakat antara bahasa Indonesia dengan bahasa daerah ditentukan oleh beberapa indikator, antara lain kelas sosial, usia, wilayah pemakaian, serta situasi pemakaian. Dengan demikian, bahasa Indonesia cenderung digunakan oleh anggota masyarakat berusia muda yang memiliki kelas sosial tinggi serta tinggal di wilayah perkotaan. Sebaliknya, anggota masyarakat yang berusia lebih tua dengan strata sosial relatif rendah yang tinggal jauh dari pusat kota cenderung menggunakan bahasa daerah (Abdullah dalam Wijana, 2013: 33)

Faktor lain penyebab pergeseran bahasa di antaranya yaitu tingkat ekonomi serta pendidikan yang dimiliki oleh individu maupun masyarakat (Sumarsono dan Partana, 2002: 237). Bahasa Indonesia merupakan bahasa pengantar resmi yang digunakan oleh lembaga pendidikan formal di Indonesia. Sekolah sebagai lembaga pendidikan formal sering mengajarkan bahasa Indonesia kepada para peserta didik. Komunikasi antara guru dengan peserta didik dalam kegiatan belajar mengajar otomatis menggunakan bahasa Indonesia sebagai bahasa pengantar. Semakin tinggi tingkat pendidikan maka strata sosial maupun ekonomi akan cenderung lebih tinggi. Hal tersebut menyebabkan masifnya penggunaan bahasa Indonesia daripada bahasa daerah dalam interaksi maupun komunikasi antar individu di masyarakat.

Menurut Triyono (2006: 3), pada dasarnya pergeseran suatu bahasa daerah disebabkan oleh adanya penggunaan code switching dan code mixing, atau sering disebut dengan istilah campur kode alih kode dan. Hal tersebut sebagai akibat adanya beralihnya kebiasaan penggunaan daerah, misalnya bahasa Jawa beralih ke bahasa Indonesia untuk percakapan dan komunikasi sehari-hari di lingkungan 
keluarga maupun kerabat yang berasal dari suku Jawa. Secara lebih rinci, ada kemungkinan besar bahwa penyebab pergeseran bahasa daerah ke bahasa Indonesia dapat dipengaruhi oleh tingkat pendidikan, perbedaan kelompok umur, jenis kelamin, wilayah pemukiman, serta adanya perbedaan etnis maupun adat istiadat asal penutur.

\section{PEMILIHAN BAHASA}

Berbicara tentang pergeseran dan pemertahanan bahasa, maka berkaitan erat dengan pemilihan bahasa. Sebuah masyarakat dengan dua atau lebih bahasa memiliki banyak kode yang berupa variasi bahasa, gaya bahasa, maupun dialek dalam interaksi dan komunikasi sosial. Penutur ketika berkomunikasi dengan menggunakan dua bahasa atau lebih maka harus memilih kode atau bahasa mana yang harus digunakan. Pemilihan bahasa tersebut tidak sesederhanan seperti yang dipikirkan, yaitu memilih salah satu bahasa secara keseluruhan dalam sebuah interaksi dan komunikasi. Dengan demikian, penutur akan memilih salah satu kode yang ada di masyarakat sesuai dengan situasi kondisi yang ada maupun faktor sosial budayayang berlaku di suatu masyarakat. (Fasold, 1984:180)

Dalam proses pemilihan bahasa yang akan digunakan, ada beberapa kode yang harus dipilih oleh penutur. Pertama, dengan alih kode atau code switching yaitu menggunakan suatu bahasa pada salah satu domain serta menggunakan bahasa lain pada domain yang lain, misal peralihan bahasa Jawa ke bahasa Indonesia. Kedua, dengan campur kode atau code mixing yaitu menggunakan salah satu bahasa tertentu yang dicampuri beberapa istilah maupun kosakata dari bahasa lain, misalnya memasukkan beberapa kosakata bahasa Inggris ke bahasa Indonesia. Ketiga, dengan menggunakan salah satu variasi atau ragambahasa dalam komunikasi dan interaksi, yang artinya tetap mempertahankan satu bahasa yang sudah ada. (Mujid F Amin dan Suyanto, 2017: 4)

Menurut Fishman, pengkajian pemilihan bahasa dapat dilakukan dengan berdasarkan wilayah (domain) atau suatu konteks situasi dan kondisi, yang dapat menunjukkan bahwa kecenderungan penutur dalam memilih serta menggunakan salah satu ragam tertentu dari pada ragam yang lain. Domain adalah konstelasi yang berkaitan dengan faktor topik, lokasi, serta partisipan. Oleh sebab itu, ada beberapa contoh domain dalam pemilihan bahasa, antara lain keluarga, teman, tetangga, pendidikan, perdagangan, serta pemerintahan. Apabila ada penutur yang berkomunikasi dalam ranah keluarga, maka penutur tersebut berada pada domain keluarga. Hal tersebut berkaitan dengan analisis diglosia karena mempunyai ciri yaitu terdapat domain yang memiliki sifat formal maupun tidak formal. Masyarakat yang memiliki sifat diglosik maka variasi bahasa yang digunakan pada domain tidak formal cenderung menggunakan variasi bahasa yang rendah, sedangkan dalam domain dengan sifat formal maka akan menggunakan variasi bahasa yang tinggi. Oleh sebab itu, pemilihan satu bahasa maupun ragam bahasa dipengaruhi pada domain yang ada. (Chaer \& Agustina, 2010: 204)

Fenomena pergeseran penggunaan bahasa pada masyarakat bilingual atau multilingual yang memiliki mengharuskan penutur untuk memilih salah satu variasi maupun ragam bahasa yang akan digunakan. Pemilihan bahasa tersebut 
menyesuaikan situasi maupun kondisi yang berlaku pada peristiwa interaksi dan komunikasi, tanpa terkecuali komunikasi yang terjadi pada ranah keluarga. Banyaknya faktor-faktor baik kebahasaan maupun nonkebahasaan dalam suatu keluarga sedikit banyak akan menyebabkan pergesaran bahasa. Dalam konteks penelitian ini, faktor-faktor tersebut menyebabkan pergeseran penggunaan bahasa Jawa ke bahasa Indonesia sebagai bahasa komunikas dalam keluarga. Adapun bahasa Indonesia yang dipilih yaitu bahasa Indonesia ragam nonformal baik yang berupa alih kode maupun campur kode.

\section{E. PENYEBAB PERGESERAN PENGGUNAAN BAHASA JAWA KE BAHASA INDONESIA DALAM KOMUNIKASI KELUARGA DI SLEMAN}

Berdasarkan uraian teori dan hasil penelitian tentang pergeseran bahasa, maka tulisan ini menguraikan beberapa faktor penyebab pergeseran penggunaan bahasa Jawa ke bahasa Indonesia dalam komunikasi keluarga di Kabupaten Sleman, Yogyakarta. Beberapa faktor tersebut, yaitu sebagai berikut.

\section{Tingkat Pendidikan Keluarga}

Menurut data Kopertis Wilayah V yang diterbitkan oleh Ristekdikti tahun 2015, terdapat 106 perguruan tinggi yang tersebar di seluruh wilayah DIY baik negeri maupun swasta. Dari total jumlah perguruan tinggi, jumlah terbanyak berada di Kabupaten Sleman, yaitu sebesar 39\%, urutan kedua yaitu Kota Yogyakarta sebesar 35\%, sedangkan Kabupaten Bantul di urutan ke tiga dengan jumlah 25\%. Sementara Kabupaten Kulonprogo dan Gunung Kidul hanya $1 \%$ dari total jumlah perguruan tinggi. Jumlah perguruan tinggi tersebut dapat bertambah tiap tahun. Hal tersebut membuktikan Kabupaten Sleman merupakan pusat pendidikan tinggi di Daerah Istimewa Yogyakarta.

Tingginya jumlah perguruan tinggi sejalan dengan tingginya jumlah pendidikan dasar, menengah, serta atas. Berdasarkan data Pemerintah Kabupaten Sleman melalui website resminya disampaikan bahwa tahun 2015 jumlah PAUD mengalami peningkatan yang cukup signifikan.Banyaknya jumlah dan jenislembaga pendidikan baik formal maupun nonformal tersebut berdampak pada mudahnya masyarakat memperoleh akses pendidikan. Menurut data Jumlah penduduk berdasarkan tingkat pendidikan Kabupaten Sleman tahun 2019, sekitar $75 \%$ dari total jumlah penduduk Kabupaten Sleman sedang dan sudah menempuh pendidikan dari SD hingga SMA/SLTA. Sedangkan penduduk yang berpendidikan tinggi (D1-S3) sebesar 15\% dari total jumlah penduduk. Dapat disimpulkan bahwa tingkat pendidikan yang dimiliki oleh anggota keluarga di Kabupaten Sleman masuk kategori tinggi.

Bahasa Indonesia masuk ke dalam kurikulum nasional yang berupa mata kuliah, mata pelajaran, atau materi wajib dipelajari oleh seluruh peserta didik baik di tingkat dasar maupun perguruan tinggi di Indonesia. Mulyati (2015, 17-18) serta Perpres No. 63 tahun 2019 pasal 23 menyebutkan bahwa salah satu kedudukan bahasa Indonesia sebagai bahasa negara yaitu sebagai bahasa pengantar dalam dunia pendidikan nasional. Bahasa Indonesia dipakai sebagai bahasa pengantar pendidikan mulai dari taman kanak-kanak sampai 
ke perguruan tinggi. Penggunakan bahasa Indonesia sebagai sarana pengembangan budaya, ilmu pengetahuan, teknologi, sastra dan seni di lembaga pendidikan semakin masif.

Selain sebagai bahasa pengatar dalam kegiatan belajar mengajar, bahasa Indonesia juga digunakan sebagai bahasa komunikasi di luar kegiatan belajar mengajar di lingkungan lembaga pendidikan. Hal tersebut secara sadar maupun tidak sadar, menyebabkan masyarakat terbiasa menggunakan bahasa Indonesia sebagai bahasa komunikasi dan interaksi sehari-hari baik di lembaga pendidikan, lingkungan masayarakat, maupun keluarga. Oleh sebab itu, tingginya tingkat pendidikan keluarga di Kabupaten Sleman merupakan salah satu faktor penyebab tingginya penggunaan bahasa Indonesia dalam komunikasi ranah keluarga.Berdasarkan hasil penelitian dapat dibuktikan bahwa semakin tinggi tingkat pendidikan maka semakin tinggi intensitas penggunaan bahasa Indonesia dalam komunikasi sehari-hari.

\section{Pemilihan Bahasa yang Lugas dan Sopan dalam Keluarga}

Wilayah Sleman terdapat dua bahasa yang paling dominan, yaitu bahasa daerah yang berupa bahasa Indonesia terutama ragam nonformal dan bahasa Jawa. Di masyarakat Jawa, terutama Sleman, kedua bahasa tersebut juga digunakan sebagai bahasa ibu atau bahasa komunikasi di ranah keluarga. Strata atau tingkat tutur bahasa yang dimiliki bahasa Indonesia berbeda dengan bahasa Jawa. Bahasa Indonesia hanya memiliki dua tingkat tutur bahasa, yaitu baku dan tidak baku atau resmi dan tidak resmi. Sedangkan Bahasa Jawa memiliki empat ragam atau tingkat tutur bahasa, yaitu krama alus, krama, lugu, ngoko alus, dan ngoko lugu.

Menurut Sasangka (2010: 119-125) bahasa Jawa memiliki dua tingkat tutur yaitu krama dan ngoko, kemudian masing-masing dibedakan lagi sehingga menjadi 4 tingkat tutur, yaitu krama alus, krama lugu, ngoko alus, dan ngoko lugu. Setiap tingkatan bahasa Jawa memiliki kosakata dan sasaran bicara yang berbeda. Bahasa Jawa krama alus atau inggil, dalam bahasa Indonesia berarti krama halus atau tinggi merupakan unggah-ungguh atau tata krama bahasa Jawa dengan tataran paling tinggi. Bahasa tersebut memiliki kadar kehalusan bahasa yang tinggi di setiap bentuk kata. Masyarakat Jawa sangat menjunjung tinggi tata krama dan kesopanan atau yang disebut dengan unggah-ungguh, sehingga penggunaan bahasa Jawa krama merupakan salah satu wujud penerapan tata krama dan kesopanan. Penggunaan tingkat tutur tersebut tentu saja menyesuaikan situasi kondisi maupun lawan bicara.

Dalam interaksi dan komunikasi keluarga di Kabupaten Sleman, ada peraturan yang tidak tertulis bahwa masyarakat Jawa dianjurkan menggunakan bahasa yang sesuai dengan unggah-ungguh atau etika, yaitu menggunakan bahasa Jawa krama. Di satu sisi, masyarakat Kabupaten Sleman terbiasa menggunakan bahasa Jawa ngoko lugu yang netral tanpa ada leksikon krama sertabahasa Indonesia nonformal pada interaksi sehari-hari. Selain tidak mudah dipelajari karena mempunyai bamyak variasi diksi, bahasa Jawa 
dengan leksikon krama, diangap kurang efektif digunakan untuk komunikasi sehari-hari dalam keluarga. Walaupun menunjukkan unggah-ungguh, tetapi penggunaan bahasa Jawa dengan leksikon krama justru dianggap tidak menunjukkan keakraban dalam interaksi keluarga. Dengan demikian, terdapat dua pilihan bahasa yang dapat digunakan dalam interaksi keluarga, yaitu bahasa Jawa ngoko lugu atau bahasa Indonesia ragam nonformal.

Dari uraian tersebut, maka faktor penyebab pergesaran selanjutnya yaitu pemilihan bahasa yang dianggap lebih komunikatif dan lugas namun tetap dianggap mempunyai nilai kesopanan. Maka banyak keluarga di Sleman, terutama orang tua yang berkomunikasi dengan anaknya menggunakan bahasa Indonesia nonformal. Secara otomatis anak juga akan menggunakan bahasa yang dipakai oleh orang tuanya. Bahasa Indonesia tersebut dianggap lebih komunikatif dan lugas daripada bahasa Jawa dengan leksikon krama, tetapi lebih sopan dari pada bahasa Jawa ngoko lugu. Dapat disimpulkan bahwa penggunaan Bahasa Indonesia dalam komunikasi keluarga tersebut bertujuan untuk menghindari kesalahan dan ketidaksopanan dalam berbahasa.

\section{Usia Keluarga}

Menurut Hidayah (2013: 20) menyatakan fakta bahwa di zaman modern ini bahasa nusantara, salah satunya bahasa Jawa, mengalami krisis perkembangan karena masuknya berbagai pengaruh asing. Penggunaan bahasa pada keluarga Jawa pada saat ini mulai berubah. Misalnya, keluarga Jawa di daerah Semarang yang mayoritas menggunakan bahasa Jawa untuk berkomunikasi mulai tergantikan oleh bahasa Indonesia. Di daerah tersebut, kelompok usia tua pada umumnya masih mampu menggunakan bahasa Jawa sesuai dengan tingkat tutur. Akan tetapi, kelompok usia muda cenderung kesulitan menguasai bahasa Jawa dengan berbagai tingkat tutur. Kelompok usia muda tersebut hanya mampu menguasi bahasa Jawa ngoko dan mulai menggunakan bahasa Indonesia sebagai bahasa komunikasi.

Hal tersebut sebenarnya merupakan fenomena umum yang terjadi di daerah penutur bahasa Jawa, terutama di daerah perkotaan, salah satunya Kabupaten Sleman.Dalam penelitian ini ditemukan fakta bahwa keluarga usia muda atau usia suami dan istri di bawah 50 tahun di Kabupaten Sleman cenderung menggunakan bahasa Indonesia untuk berinteraksi dan berkomunikasi dalam keluarga. Bahasa Indonesia pada umumnyadigunakan saat interkasi dan berkomunikasi antara orang tua dengan anak. Keluarga usia muda tersebut banyak yang mengalami kesulitan menggunakan bahasa Jawa terutama Jawa karma ketika berkomunikasi di dalam keluarga. Di satu sisi, bahasa penggunaan Jawa ngoko dianggap memiliki unggah-ungguh yang rendah. Oleh sebab itu, bahasa Indonesia digunakan secara massif oleh keluarga-keluarga muda. 


\section{Stratifikasi Sosial Keluarga}

Sneddon (2003, 140-142) menyatakan bahwa bahasa Indonesia telah mendapatkan status sebagai bahasa yang mempunyai nilai prestise atau nilai kewibawaan dibandingkan dengan bahasa-bahasa daerah yang dimiliki oleh Indonesia. Bahasa Indonesia dianggap sebagai bahasa bagi golongan menengah yang berpendidikan, bahkan dianggap bahasa elit di Indonesia. Dengan kata lain, bahasa Indonesia adalah bahasa masyarakat yang memiliki stratifikasi sosial tinggi dan menenengah. Dalam berbicara, seseorang yang merasa memiliki stratifikasi sosial yang tinggi akan menggunakan bahasa Indonesia agar tujuan kewibawaan tetap terjaga.

Stratifikasi sosial menurut Sorokin (1998: 36) adalah perbedaan masyarakat ke dalam beberapa kelas secara bertingkat yang dibedakan menjadimasyarakat kelas tinggi, sedang atau menengah, serta rendah. Indikator untuk menentukan stratifikasi sosial dalam sebuah komunitas atau masyarakat, antara lain: tingkat pendidikan, jenis pekerjaan, ukuran kekayaan, kekuasaan dan kewenangan, serta kehormatan. Indikator tersebut juga berlaku di masyarakat atau keluarga di Kabupaten Sleman, karena pada dasarnya masyarakat Jawa dikenal sebagai masyarakat yang masih menganut sistem kelas-kelas sosial.

Berdasarkan fakta yang ditemukan, stratifikasi sosial yang dimiliki oleh keluarga di Kabupaten Sleman berpengaruh dalam pemilihan dan pergeseran bahasa yang digunakan dalam komunikasi keluarga. Keluarga yang memiliki stratifikasi sosial yang menengah maupun tinggi lebih sering menggunakan bahasa Indonesia dalam berkomunikasi di ranah keluarga. Sedangkan stratifikasi sosial rendah biasanya akan tetap mempertahankan bahasa ibu atau bahasa asli yaitu bahasa Jawa ngoko.Misalnya, keluarga yang berprofesi dibidang formal (pegawai perkantoran dan TNI/Polri/ASN) akan lebih sering menggunakan bahasa Indonesia dibandingkan dengan keluarga yang berprofesi di bidang nonformal (petani, pedagang, serta buruh).

\section{Kurangnya pembelajaran Bahasa Jawa untuk Keluarga}

Bahasa Jawa merupakan Bahasa daerah yang menerapkan falsafah tumata, yang artinya menata dan menempatkan lawan bicara pada tempat yang semestinya sesuai dengan strata sosial yang dimililki. Maka dalam bahasa Jawa terdapat variasi dan bentuk bahasa yang kompleks, yaitu ngoko lugu, ngoko andhap, madhya, madhyantara, krama, dan krama inggil. Oleh sebab itu, banyak masyarakat Jawa yang merasa kesulitan belajar bahasa Jawa terutama di tingkat madhya dan karma. Selain itu, bahasa Jawa dianggap sebagai bahasa yang cukup sulit dan rumit untuk dipelajari secara mendalam. (Edi, 2014: 36)

Dalam kurikulum pendidikan nasional, terutama untuk jenjang sekolah dasar dan menengah, mata pelajaran bahasa Jawa hanya mendapatkan porsi yang lebih sedikit dibandingkan mata pelajaran bahasa Inggris dan bahasa Indonesia. Ditambah lagi, bahwa bahasa Indonesia adalah bahasa resmi dalam dunia pendidikan. Hal tersebut cukup beralasan karena mata pelajaran bahasa 
Jawa merupakan muatan lokal, seperti yang termuat dalam Undang-undang Nomor 20 Tahun2013 tentang Sistem Pendidikan Nasional. Padahal kompetensi berbahasa yang akan dicapai dalam dalam pembelajaran Bahasa Jawa cukup kompleks. Kompetensi tersebut yaitu, mendengar, berbicara, membaca, dan menulis yang bertujuan agar peserta didik dapat menggunakan bahasa Jawa dengan santun sesuai dengan nilai-nilai budi pekerti adiluhung yang ada di budaya Jawa.

Selain kurangnya pembelajaran bahasa Jawa pada lembaga pendidikan formal, beberapa keluarga di Kabupaten Sleman juga merasa bahwa pembelajaran bahasa Jawa di lingkungan keluarga juga sangat terbatas. Mereka menganggap bahwa variasi bahasa Jawa mulai dari ngoko sampai kromo sangat sulit dipelajari secara mendalam. Beberapa orang tua menganggap bahwa mereke tidak punya kemampuan untuk mengajarkan bahasa Jawa secara mendalam kepada anak-anaknya. Banyak perbedaan diksi dan kosakata untuk menyebutkan suatu hal yang sebenarnya sama. Dampaknya, beberapa keluarga lebih memilih bahasa Indonesia sebagai bahasa komunikasi dalam keluarga.

\section{Wilayah Pemukiman Keluarga}

Menurut Peraturan Menteri Dalam Negeri No. 137 tahun 2017 tentang Kode dan Data Wilayah Administrasi Pemerintah, seluruh wilayah di Kabupaten Sleman masih dikategorikan desa, bukan kategori kelurahan. Akan tetapi, sebagian besar wilayah daerah Sleman merupakan daerah perkotaan yang merupakan pusat ekonomi dan pendidikan. Beberapa kecamatan, yaitu Kecamatan Depok dan Mlati merupakan daerah perkotaan yang berbatasan langsung dengan ibu kota D. I Yogyakarta. Dalam penelitian ini ditemukan fakta bahwa penggunaan bahasa Indonesia untuk komunikasi keluarga lebih banyak ditemukan pada keluarga yang bermukim di wilayah perkotaan atau daerah yang berbatasan langsung dengan ibu kota, yaitu di Kecamatan Depok dan Mlati. Penggunaan bahasa Indonesia tersebut akan semakin terlihat pada pola komunikasi maupun interaksi antara orang tua dengan anak. Daerah atau lingkungan perkotaan lebih sering menggunakan bahasa Indonesia sebagai bahasa ibu dari pada daerah atau lingkungan pedesaan.

\section{Sikap Keluarga terhadap Bahasa}

Sudah diuraikan sebelumnya bahwa bahasa Indonesia diangap sebagai bahasa berprestise yang digunakan oleh masyarakat dengan stratifikasi sosial yang tinggi. Walaupun demikian, bukan berarti anggota masyarakat dengan stratifikasi sosial rendah tidak mau menggunakan bahasa Indonesia. Faktanya, banyak keluarga dengan stratifikasi sosial menengah dan rendah yang menggunakan bahasa Indonesia dalam komunikasi keluargadi Kabupaten Sleman. Bahasa Indonesia tetap dianggap sebagai bahasa yang prestisius yang seolah-olah dapat menaikkan kelas sosial yang dimiliki keluarga. Dengan menggunakan bahasa Indonesia, keluarga dengan kelas sosial rendah merasa menjadi keluarga yang modern bagian dari kelas sosial yang lebih tinggi. Hal 
tersebut merupakan bentuk sikap keluarga di Kabupaten Sleman terhadap bahasa.

\section{F. SIMPULAN}

Penutur bahasa Indonesia terus bertambah pesat setiap dasawarsa. Bahasa Indonesia mulai menggeser peranan bahasa daerah sebagai bahasa ibu di lingkungan keluarga. Salah satu bahasa daerah yang mengalami pergeseran yang cukup tinggi yaitu bahasa Jawa. Kabupaten Sleman D.I Yogyakarta merupakan salah satu wilayah masyarakat penutur asli bahasa Jawa yang sangat menjunjung tinggi unggah-ungguh dan budaya Jawa. Di sisi lain, Kabupaten Sleman merupakan daerah yang mempunyai tingkat keragaman dan pertumbuhan yang tinggi. Oleh sebab itu, Kabupaten Sleman rentan mengalami pergeseran dari bahasa Jawa ke bahasa Indonesia sebagai dampak pemilihan maupun pemertahanan bahasa. Pergeseran bahasa tersebut salah satunya terjadi dalam interaksi dan komunikasi di ranah keluarga. Beberapa faktor penyebab adanya pergeseran bahasa tersebut, antara lain: tingkat pendidikan keluarga, pemilihan bahasa yang lugas dan sopan dalam keluarga, usia keluarga, stratifikasi sosial keluarga, kurangnya pembelajaran bahasa Jawa untuk keluarga, wilayah pemukiman keluarga, serta sikap keluarga terhadap bahasa. Bahasa Indonesia yang digunakan dalam interaksi dan komunikasi keluarga di Kabupaten Sleman didominasi oleh bahasa Indonesia nonformal yang disertai dengan gejala alih kode dan campur kode.

\section{DAFTAR PUSTAKA}

Arafik, M dan Rumidjan. (2016). "Profil Pembelajaran Unggah-Ungguh Bahasa Jawa di Sekolah Dasar." Jurnal Sekolah Dasar: Kajian Teori dan Praktik Pendidikan 25 (1).

Chaer, Abdul dan Leonie Agustina. (2010). Sosiolinguistik: Perkenalan Awal. Jakarta: Rineka Cipta.

Coulmas, F. (2005). Sociolinguistics: The Study of Speakers' Choice. Cambridge University Press.

F Amin,Mujid danSuyanto. (2017). "Pergeseran dan Pemertahanan Bahasa Ibu Dalam Ranah Rumah Tangga Migran di Kota Semarang." Jurnal Nusa 12 (1).

Fasold, Ralp. (1984). Sociolinguistics of Society. New York: Basil Blackwell.

Fitri Hidayah, Nur. (2013). "Krisis Eksistensi Penggunaan Bahasa Jawa dalam Keluarga Jawa (Studi Kasus di Dusun Siroto Kelurahan Susukan Kecamatan Ungaran Timur Kabupaten Semarang)." SOLIDARITY: Journal of Education, Society and Culture 2 (2).

Hasan, Akhmad Muawal dan Amika Wardhana. (2016). "Praktik Multikulturalisme di Yogyakarta: Integrasi dan Akomodasi Mahasiswa Papua Asrama Deiyai.” Jurnal E-Societas 5 (3). 
Ibrahim, dkk, (2019). "Faktor Sosial yang Berpengaruh terhadap Pergeseran Bahasa Lowa." Jurnal KEMBARA 5 (2).

Jatmiko, Edy. (2014). “Tembung lan Gambare (Kamus Visual Ragam Diksi Bahasa Jawa Tingkat Ngoko)." DEKAVE: Jurnal Disain Komunikasi Visual 7 (2).

Mulyati. (2015). Terampil Berbahasa Indonesia. Jakarta: Prenadamedia Group.

Nababan, P.W.J. (1991). Sosiolinguistik: Suatu Pengantar. Jakarta: PT Gramedia Pustaka Utama.

Sasangka, Tjatur Wisnu. (2010). Unggah-ungguh Bahasa Jawa. Jakarta: Yayasan Paramalingua.

Sneddon, J.N. (2003). The Indonesia Language: its History and Role in ModernSociety. Australia: University of South Wales.

Soemarsono. (2012). Sosiolinguistik. Yogyakarta: Pustaka Pelajar.

Sorokin, Pitirin A. (1998). Social Stratification. New York: Harper.

Sumarsana dan Paina Partana. (2002). Sosiolinguistik. Yogyakarta: Sabda dan Pustaka Pelajar.

Suyata, Pujiyati dan Suharti. (2007). "Status Isiolek Yogyakarta-Surakarta dan Implikasinya terhadap bahasa Jawa Standar." Jurnal Litera 6 (1).

Tamrin. (2018). Pola Pergeseran Bahasa: Kasus Pergeseran Bahasa Totoli dalam Ranah Keluarga Berdasarkan Hubungan Peran dan Kategori Umur di Kabupaten Tolitoli. Balai Bahasa Provinsi Sulawesi Tengah.

Triyono, Sulis. (2006). "Pembahasan Hasil Penelitian: Pergeseran Bahasa Daerah Akibat Kontak Bahasa Melalui Pembauran." LITERA (Jurnal Penelitian Bahasa, Sastra, dan Pengajarannya) 5 (1).

Wijana, I Dewa Putu. (2013). Sosiolinguistik: Kajian Teori dan Analisis. Cetakan V. Yogyakarta: Pustaka Pelajar. 